\title{
The Role of China Seminars in Building Other Developing Countries: An Experience Case in Sierra Leone
}

\author{
Alhaji Bakar Kamara \\ Correspondence: Alhaji Bakar Kamara, Department of Curriculum and Teaching Methodology, Central China Normal \\ University, Wuhan, China; Department of Education, Milton Margai College of Education and Technology, Freetown, \\ Sierra Leone. E-mail: bakarkamara10121@gmail.com
}

\author{
Received: May 5, 2019 \\ Accepted: June 5, 2019 \\ Online Published: June 6, 2019 \\ doi:10.11114/smc.v7i1.4316 \\ URL: https://doi.org/10.11114/smc.v7i1.4316
}

\begin{abstract}
This paper shows an experience gained during the touring and visitation of various cities in China. It focuses on the experience from the seminars attended in China in 2013 and 2016. It shows some of what was learnt, experiences gained, and a food for thought for the author upon returning home. The paper starts with a background and introduction of China, and the seminars that are conducted to help empower other developing countries. It then shows a reflection of Sierra Leone and China Relationship. The paper then throws light on the seminars conducted in China and the conditions that participants should know about these seminars. In a clearer picture, the paper highlights the subject matter schedule for the entire seminar with some few benefits of lectures about China. Also a snap shot of cities that are visited and a background of some important cities like Beijing and Shanghai. The author indicates the relevance and significant of the seminars in China. Finally some recommendations were made to the organizers of the seminars.
\end{abstract}

Keywords: experience, seminar, training, benefit

\section{Introduction and Background}

As proposed in the previous paper entitled; "Chinese Films, Traditions and Cultural Heritage-An Impact in Sierra Leone", published in the European Journal of Social Sciences Studies in 2018, this paper continues to view the reality in China through participating in seminars. It is a brief sharing of the experiences and Knowledge gained and observed in the seminars in China. In order to briefly present a snapshot of the experiences and knowledge, the researcher revealed the observable elements of interest within the scope of a primary data, supplemented with some references. In the analysis of this paper, the researcher used qualitative method in explaining the experience gained, felt and observed. To strengthen the paper, reference sources from secondary data was also employed. The researcher included pictures of the seminars to illustrate more clarity of the paper.

The People's Republic of China named China for short is situated in the east of Asia and western coast of the pacific. The land area is about 9,600,000 square Kilometers. China boundaries on fourteen countries and neighbors eight countries by sea. It is divided into 4 municipalities directly under the control of the Central Government, 23 provinces, 5 autonomous regions and 2 special administrative regions. Beijing is the capital and the national flag is the Five-Starred Red Flag. China has a total population of 1341 million (at the end of 2010) having 56 ethnic groups. Most of the country being in temperate zone and subtropical zone has a monsoon climate, and only a small area thereof is in tropical zone or near cold zone. In China, with its landscape of being higher in the west and lower in the east, there are such key landforms as mountains, plateaus, plains and hills. Qinghai-Tibet Plateau, with an average altitude of over 4,000 meters, has long been known as the "Roof of the World". China has developed as one of the economic powers worldwide with the most prospective economy for development, and the people have gotten a well-off standard of living on the whole. With the pending of the $21^{\text {st }}$ century, the Chinese government has been establishing and improving macroeconomic control and the state economy has been kept upholding a steady and rapid growth. In 2012, the GDP was 51932.2 billion RMB, up by $7.8 \%$ over the previous year (XINHUA DAILY TELEGRAPH, September 6, 2013(Friday).

China, yet a developing country, but in reality, China is speedily rising to the climax of a great nation for its wonderful offer in helping other nations develop through mutual co-existence and a community with shared characteristics. The reality is obvious when one steps a foot in any airports of China, then one would wonder the greatness of development 
in technology, infrastructure, and constructions. China freely provides great opportunity for research, education, hospitality, and attraction. Over the years, china has provided free scholarships for studies in various programs such as education, military, medicine, marine, technology and many more areas.

In addition, china also organizes seminars of various disciplines in different universities that provide training and orientation for developing countries all over the world. These trainings provide meaningful knowledge that capacitates growth in developing countries. China supports developmental project, and provide aids that salvage the unconditional instability of developing countries. As a matter of fact, Chinese are seen in all developmental projects such as road construction, building project, technology, airport construction, health promotion, defense training and many more in developing countries. China has an open policy that welcome people from all over the world through bilateral relationship and mutual understand of co-existence.

\subsection{Reflection of Sierra Leone and China Relationship}

Sierra Leone bond is patterned with melodies such as community, friendship, religion, love, Education, and politics. In recalling history, Sierra Leoneans were disgruntled with colonial rule that powered their ambition for independence. Sierra Leone got Independent on 27 April, 1961 in order to build up a platform for democracy for self-governance. Even though independent was gained, the agonizing presence of political unrest, counter coups, and civil war made the country one of the poorest, most vulnerable countries in the developing world (Mauricia John, 2013).

The bilateral relationship of Sierra Leone and China is renowned to have been on track way back in 1971. In recalling the history of Sierra Leone, one would identify the growing impact of China in Sierra Leone had its starting point on July 29, 1971, when the then president of Sierra Leone-Dr. Siaka Stevens -contracted diplomatic relationship with the People's Republic of China. So, many fruits have borne in that relationship over the past 48 years. There are tangible bilateral trade agreements to Agriculture, health care, infrastructure, fisheries, energy security and Education. Added to European Union (EU), China seemed to be Sierra Leone's second largest importer and exporter in 2010. In 2010 also, the bilateral trade reached $\$ 109$ million, and total Chinese investment was $\$ 5.2$ million. China and Sierra Leone agreed to ferment a strong and real friendship with the goal of mutual and collective Economic growth and harmonization. China being a sponsor country, the bilateral relationship would open an opportunity for Sierra Leone to have a full advantage of increasing their income from foreign investments in order to promote in their private sector development (BAH MC, 2019).

Sierra Leone has involved in developing genuine local partnership with China. As such, the relationship reinforces and builds strong state institutions that provide transparency and oversight role in the actions of government and its contributor countries. All trade discussions and infrastructural projects will be geared towards making more job predictions for the local workforce. It also increases revenues through taxes and other inducements. Besides, it is governing labor laws that protect the local market from misuse, designing laws that protect the mining, fishing, and other services. Furthermore, it covers industries from waste, deception, abuses, promoting good business social responsibility from Chinese companies and expanding the fields of foreign direct investment. These measures pave a new path to formalizing a corporation of friendship that is productive and enduring

The People's Republic of China has made a considerable development on the Freetown urban scenery starting from the multi-use national stadium to Youyi construction (ministerial complex). Over the past years, China has built power transmission, bridges, dams and so many roads. They have built the foreign ministry building, extra offices for parliament and the 100- bed China Sierra Leone friendship hospital at Jui- outside of Freetown. The former President of the Republic of Sierra Leone- Dr. Anes Bai Koroma - in 2013 contracted a deal with Chinese railway International Company to build a new airport and railway amounting in the total of $\$ 8$ billion. Therefore, China has helped Sierra Leone significantly in nation growth and development. China has also engaged in empowering all sectors of Sierra Leone society by providing scholarships opportunities for citizens to study in China in various fields of studies, such as, Education, Finance, Economics, Engineering, Sciences, Computer studies, and many more. In addition, many officers and workers from various ministries are offered the opportunity to attend international seminars and trainings for more empowerment. As one of the beneficiaries of attending many seminars in China, the author would like to share some experiences that were learnt during the seminars in China. 


\section{Yuiyi Building}

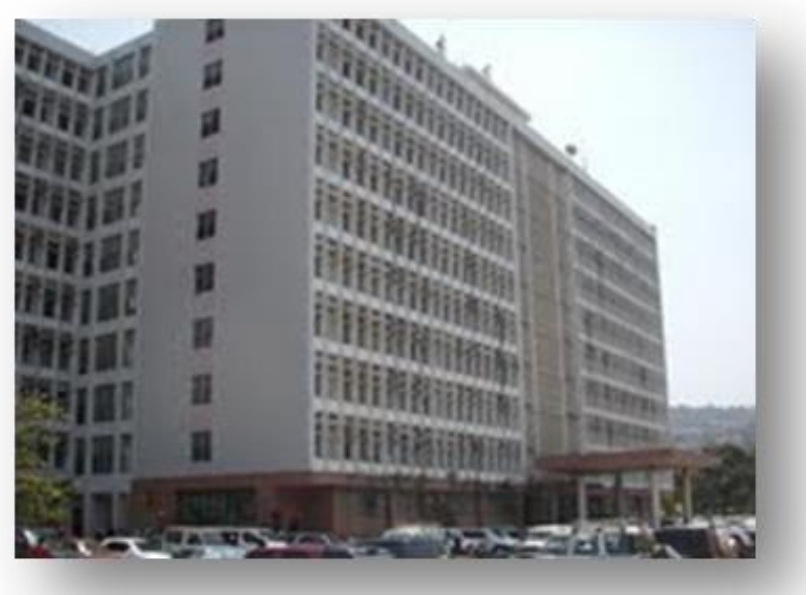

National Stadium

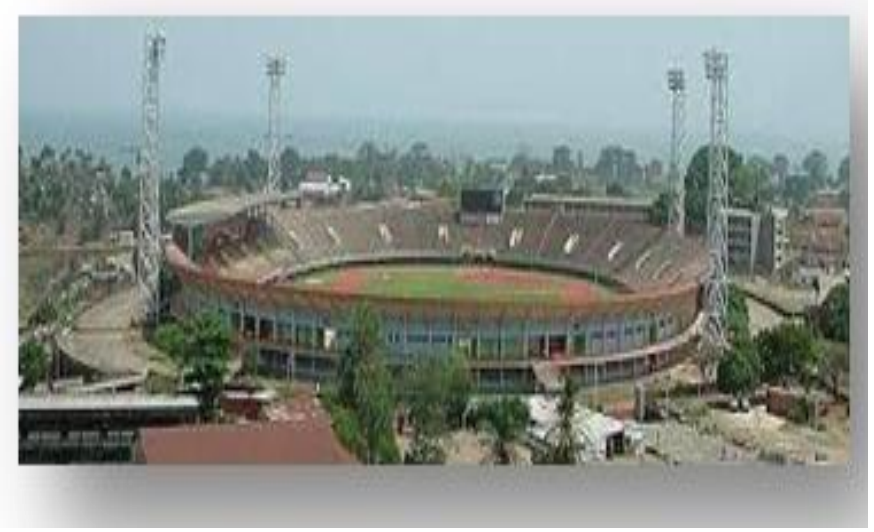

Jui Hospital

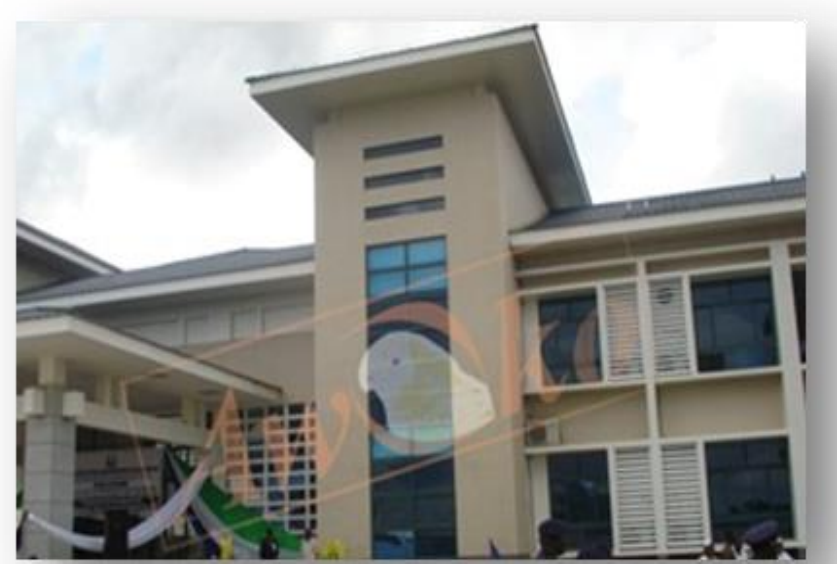

Masiaka Highway

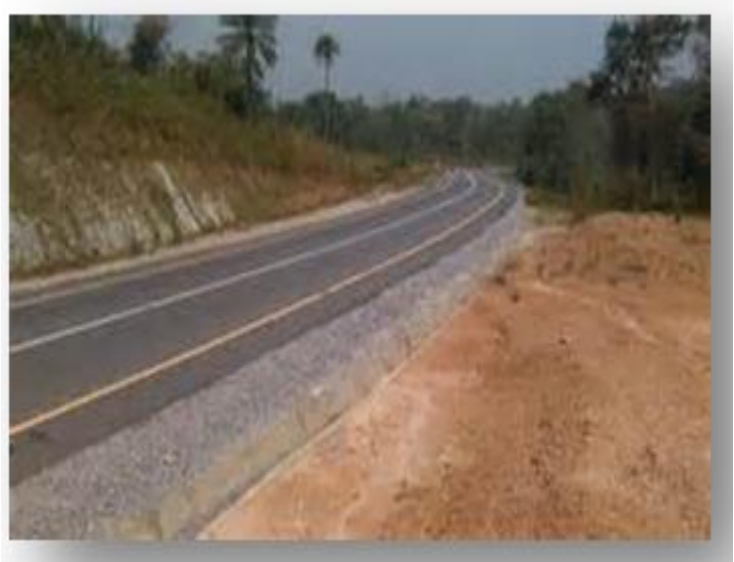

As a matter of fact, these graceful offers act as an empowerment that is leading to the development of the people of Sierra Leone. Leading to seminars, China has again offered to empower all sectors of the Sierra Leone educational institutions by providing short courses training for teachers, university presidents, college administrators and governance for African Universities /colleges. These trainings come at the right time that Sierra Leone is growing with so many Higher Institutions without much reflection to the development of the economy. China is acting as a torch light in providing remedy and solution to the problems of Sierra Leone and Africa as a whole. These seminars provide the roadmap and answers necessary for the running of an effective Higher Educational system in a country -Sierra Leone in particular. Participants have learnt from China that, it is only through knowledge and experience that people can grow and develop a higher standard of living and lower the cost of living in countries.

\subsection{Seminars Attended in China}

It is good to know that the author had participated in China seminars, and through it, is now a student in Central China Normal University (HOUZHONG UNIVERSITY) studying in curriculum and Teaching Methodology. The author had an opportunity to have visited China three times to attend seminars before the final trip for studies. The first trip was a seminar for "Educators from Developing Countries" that took place from August 28 to September 17 in 2013, organized by Northeast Normal University in Changchun, Jilin province. The second was a "Seminar for Universities Teachers from Developing Countries" organized by Northeast Normal University from June 8 to July 28, 2016 in Changchun, Jilin province. The third was a "Seminar on University Administration Capacity Building for Anglophone African Countries" organized by Zhejiang Normal University from September 11th to 31st October, 2016 in Xinhua. It was a wonderful experience and deeper insight in education, innovation and development for quantum benefit realized from these seminars.

One of the main purpose of seminars in China is to attract and expose the country into the world stay as it is opening up. Tourism, inclusive and inter-industrial, are the contemporary service industry, which can apparently boost the growth of 
its pertinent trade and industry. Developing tourism can significantly give motivation to the development of the tertiary industry, such as transportation, commercial-retail, financial service, postal and telecommunication, cultural recreation, accommodation, business convention and exhibition and so on. It similarly plays a significant and positive role in promoting the development of overall economy and society (Yang Houlan, January 25, 2013).

In addition, the seminars open a link of China with the rest of the world. It also serve an overview in understanding China. Through these seminars, China's standing in the world is growing every day - and the importance of understanding China is increasing with it. So, the Government set the pace for different local organizations and institutions to engage in building bridges between China and the rest of the world, and their China Seminars has many ways of achieving that goal. Each year, Institutions partner with schools, colleges, Universities and government agencies from around the world to create and host unforgettable short- and long-term study excursions in China for students of all ages, and workers of different professions.

In today's economic world, public and private corporations should not misjudge the significance of developing and supporting sound, internationally recognized financial reporting practices. By functioning together to offer professional education of the highest quality in this matter, Institutions in China aim to support the growth of the accounting profession in China, as well as backing to the growth and competitiveness of Chinese businesses on the global stage. Eric Schmidt, President of CEBEX Group commented that; "We are extremely pleased to be working with IASeminars to provide Chinese companies with a comprehensive range of financial training solutions," "IASeminars' significant worldwide IFRS and US GAAP training experience will give attendees a premium education opportunity, which is otherwise largely unavailable in China".(CEBEX GROUP and IASeminar, August, 2012)

\subsection{Conditions of Seminars and Scholarships}

It is important to note that, all seminars and scholarships are free from the Chinese government. All citizens of Sierra Leone are requested and told not to pay a single cent to somebody for a seminar or Chinese scholarship. Usually participants for seminars are nominated by Institutions, and they go through the ministry of foreign Affairs and International co-operations of Sierra Leone. For the safety of China and its people, all participants should be free from all diseases and have a clear free record of crime. The first examination of any participant is to go through medical examination in the Sierra Leone-China Fellowship Hospital in JUI, Freetown. In the hospital, the participants go through various tests and examinations in order to be physically and medically fit for the long journey from West Africa to China. The results of that examination are usually analyzed by the consulate office in Freetown for a final decision. Any fault detected with physical examination may deter the acceptance of the participants to travel to China. Nominated persons, who unfortunately could not go through the medical tests, are usually informed with immediate effect, and the Institutions may be requested to replace that space with other person for re-examination. The consulate office organizes orientation exercises for all the successful participants for a better understanding of all activities, tasks, expectations and conditions of the trip, journey to and from China. Participants must be aware of the fact that, the tickets provided to them by the Chinese Government for the seminar should not be changed at all. Besides, the schedule of the seminar should not be changed for other personal activities. Everything will be made known to the participants regarding the allowances to be provided, and the contact persons for the seminar; in case of any obstacle along the journey from Sierra Leone to China. Participants are advised in advance to inform organizers of seminars for any tour they wish to take in China- for safety and protection measures to be put in place for them. They are advised also not to rush in shopping, as there are schedules for touring, shopping, visitations, entertainments and studies.

\section{The Subject Matter of the Seminars Attended in China}

\subsection{First "Seminar of Educators}

First "Seminar of Educators from Developing Countries (2013)" And Second "Seminar for Universities Teachers from Developing Countries (2016)" At Changchun, Jilin Province.

These two seminars were held in Changchun. The coordinator of the seminars, Mr. Peter Zhang Lijun ,in the opening ceremony explained in brief about CHANGCHUN CITY, and the host University- NORTH EAST NORMAL UNIVERSITY that:

Changchun is the capital and large city of Jilin province, located in the Northeast of the China. Citing the 2010 census of China, Changchun had a total population of 7,674,439 under its dominion. The city's residential area, including 5 districts and 4 development areas. The name of the city means "Long Spring" in Chinese language. In the middle of 1932 and 1945, Changchun was retitled Hsinking( Chinese: literally. "new capital") by the Japanese as it grow into the capital of the Japanese puppet state manchukuo inhabiting Northeast region of China. After the foundation of China in 1954 it was Known as China"s Automobile city. Changchun is a significant industrial base with a specific focus on the automotive sector. Because of its key role in internal automobile industry, Changchun was sometimes mentioned to as 
the "Detroit of China". Apart from this industrial aspect Changchun is also one of four "National GardenCities" awarded by the Ministry of Contruction of P.R. China in 2001 due to its high urban greening rate.

Northeast Normal University (NENU) is an Institution of higher learning under the direct administration of the Ministry of Education, and one of the national key universities given construction priority of the 211 project. NENU is located in Changchun City- the beautiful Spring City of Northern China, and reputable as the cradle of teachers.
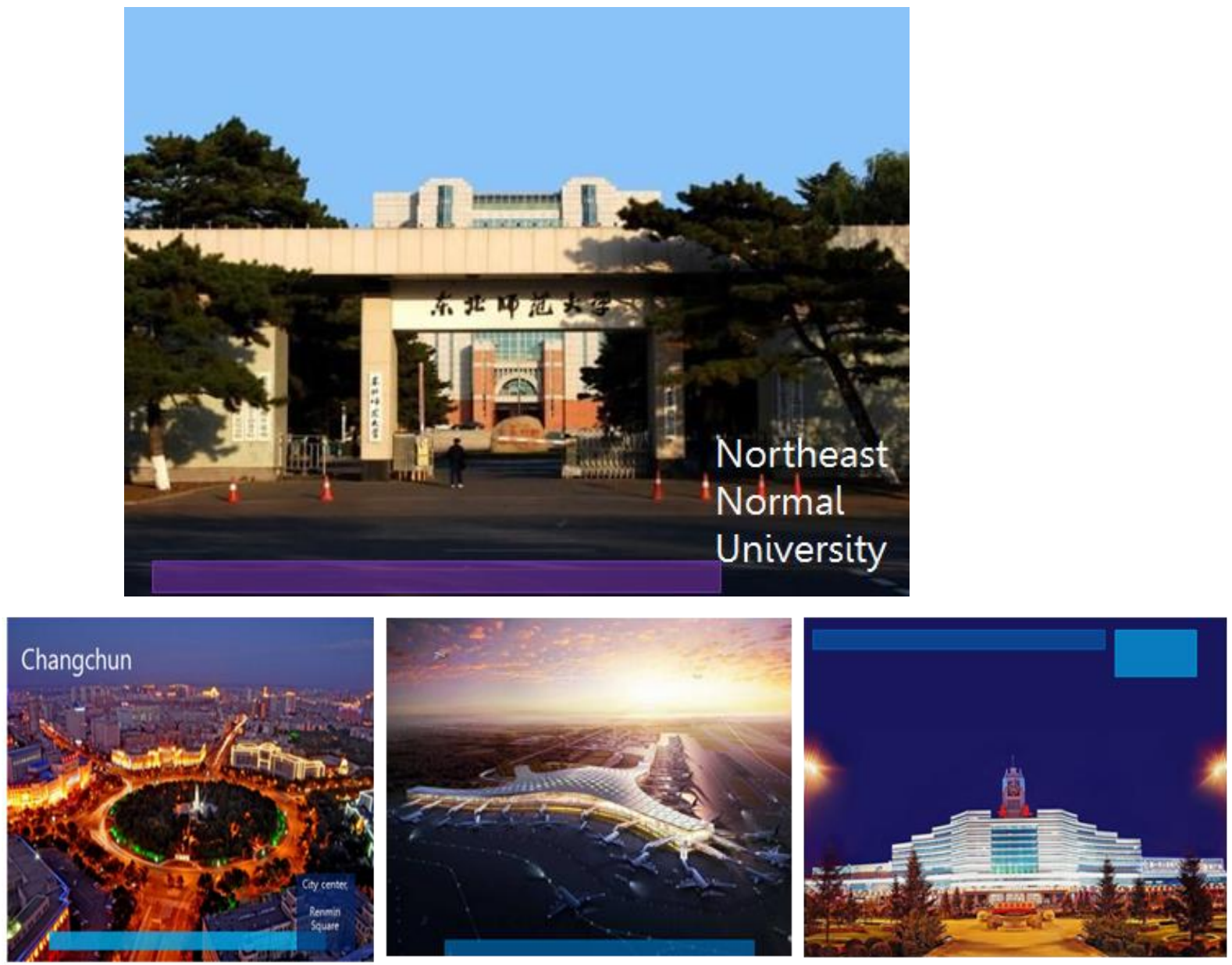

At the end of the opening ceremony, Mr. Peter concluded by analyzing the schedule that included Visitations to Museum, Campuses, Schools, and other major cities like Beijing and Shanghai. He further explained to participants regarding the facilities available in hotels such as swimming pool, Gym, Laundry, Free Wi-Fi and Money Exchange.

\subsection{Topics Covered and Lecturers-In-Charge during the Seminars}

The classes were very interesting and interactive. Professors from different schools and departments gave different lectures that center within Education and administration. In particular, the development of Chinese educational system, reforms and opening up to the world. The professors delivered lectures on various subjects that covered a range of China educational curriculum.

2.2.1 In the First Seminar for Young Educators from Developing Countries (2013), the Following Were the Topics Covered by of the Lecturers-in-Charge

1. China Economic and Social Development - Wang Xuejun

2. The Construction of China's Education Law System - Yang Yingxi

3. Accomplishment, Measures and Issues in Higher Education Reform in China - Yang Zhong

4. Development Mode of University Teachers - Jiang Ming

5. The Trends and issues of Chinese Teacher Education Reform since the late 1990 - Rao Congman

6. The Scale, Structure, and Management of China's Education - Yang Yingxiu

7. Administrative System of Education in China - Bai Weichun 
8. International cooperation and Exchanges in China's Higher Education - $\quad$ Zhang Shaojie

9. Team Development Mechanism of China's Educational Administration (Outline) - Fu Qiang

10. Outline of China's National Plan for Medium and Long-term Education Reform and Development and New Design for China's Education Reform and Development _ - Liu Haimin

11. The Construction of Modern University in China Yan Weigang

12. Reforms of Teachers' Development Strategy and Training Mode of the Basic Education in China - Sun Hejuan

13. Major Moves and Trends of China's Basic Education Reform in past Ten years - Liu Haimin

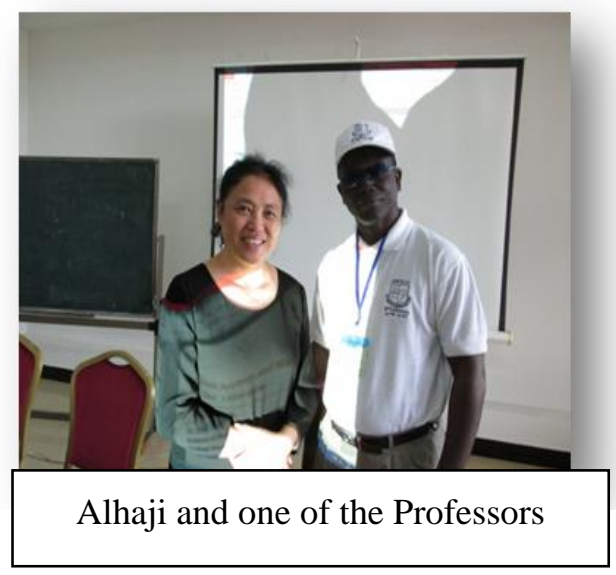

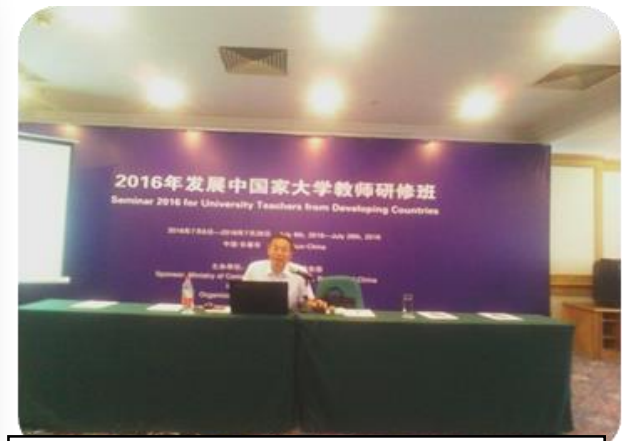

A Professor in his Presentation

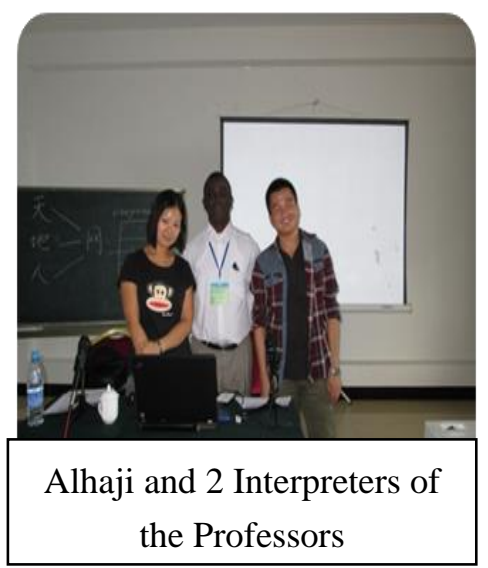

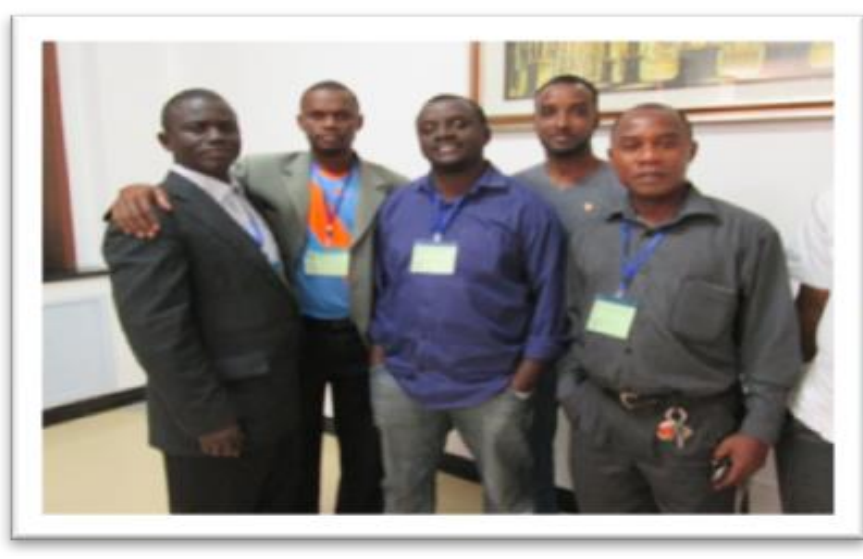

Alhaji and other Participants from other Countries

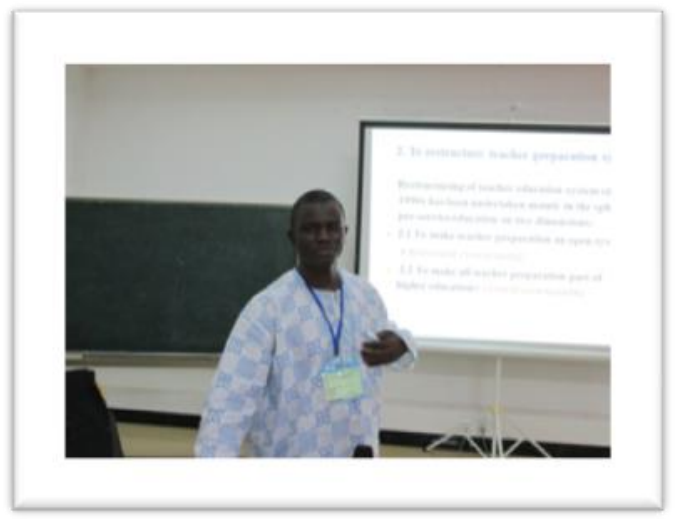

Alhaji making a Presentation

2.2.2 The Second Seminar 2016 for University Teachers from Developing Countries also Delivered the Following Lectures and Some Others

1. Outline of China's National Plan for Medium and Long-term Education Reform and Development and New Design for China's Education Reform and Development - Liu Haimin

2. The Scientific Research Mechanism of College Teachers in China _ _ Liu Jianjun

3. The Trends and issues of Chinese Teacher Education Reform since the late 1990 - Rao Congman

4. A Study of the Constructive Mechanism of Higher Learning Institution Teachers _ - Jiang Ming

5. The Construction of the Modern University System in China.

6. Education of Migrant Workers' Children.

- $\quad$ Yan Weigang

7. Basic Education Administration System in China

- $\quad$ Wang Zhichao

XIA Aue 

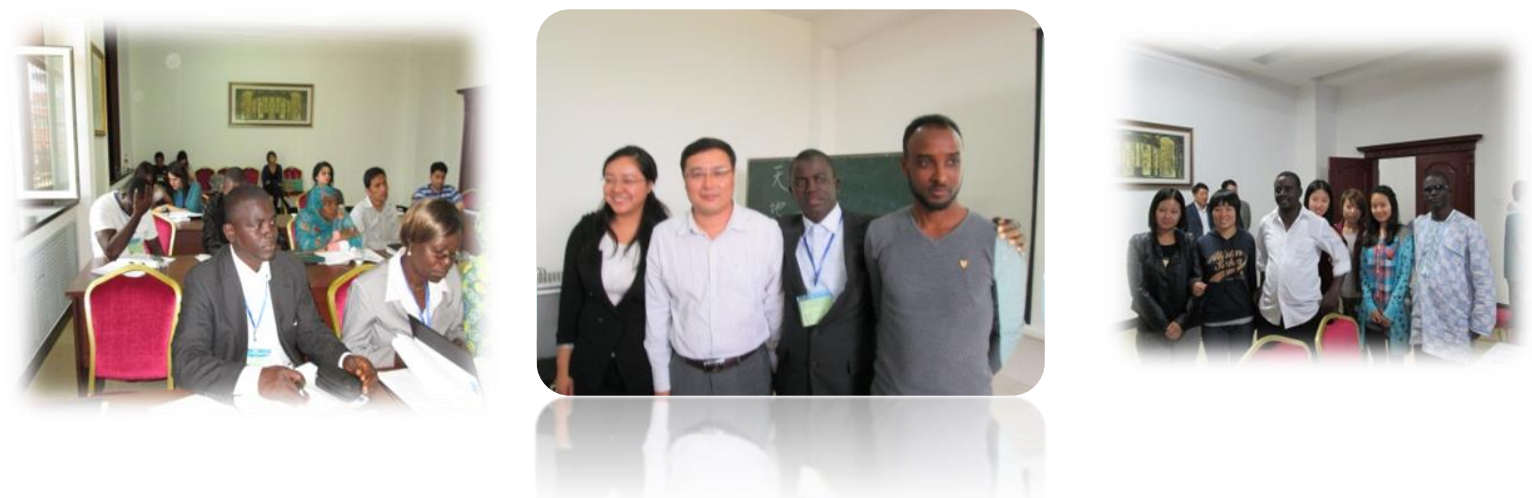

\section{Classes, lecturers and Class mate}

2.2.3 The third was a "Seminar on University Administration Capacity Building for Anglophone African Countries" organized by Zhejiang Normal University

The seminar on University capacity building for Anglophone countries in 2016, held in Zhejiang Normal University, Jinzhou Zhejiang province catalogued a complete modular set program for post graduate diploma in education that can stretch to a semester as the author suggested. The seminar covered both the theory and practical knowledge needed for an effective learning and understanding geared towards the enhancement of the eradication of illiteracy through compulsory education. The theoretic aspect covered the lectures, presentations and discussions; whilst the practical comprised of the visitations to cities and Universities.

The subject of the seminar covered the following topics:

Lecture 1

Lecture 2

Lecture 3

Lecture 4

Lecture 5

Lecture 6

Lecture 7

Lecture 8

Lecture 9

Lecture 10

Lecture 11

Lecture 12

Lecture 13

Lecture 14

Lecture 15
China's national conditions.

An overview of China's Education

The law of China's Higher Education

Postgraduate Education and degree in China

China's personnel system

Gender Equality of China's Higher Education

Experiencing Chinese culture in sports

Innovation and enterprising Education in China's HE institutions

Pains of Chinese Universities Transformation

Higher Vocational Educations in China.

Sino-Africa development and co-operation in Education

Zhejiang Normal University reaching the world stage.

Internationalization of Higher Education.

The change of Chinese HE admission policy.

Appraisals and quality maintenance of H.E. 

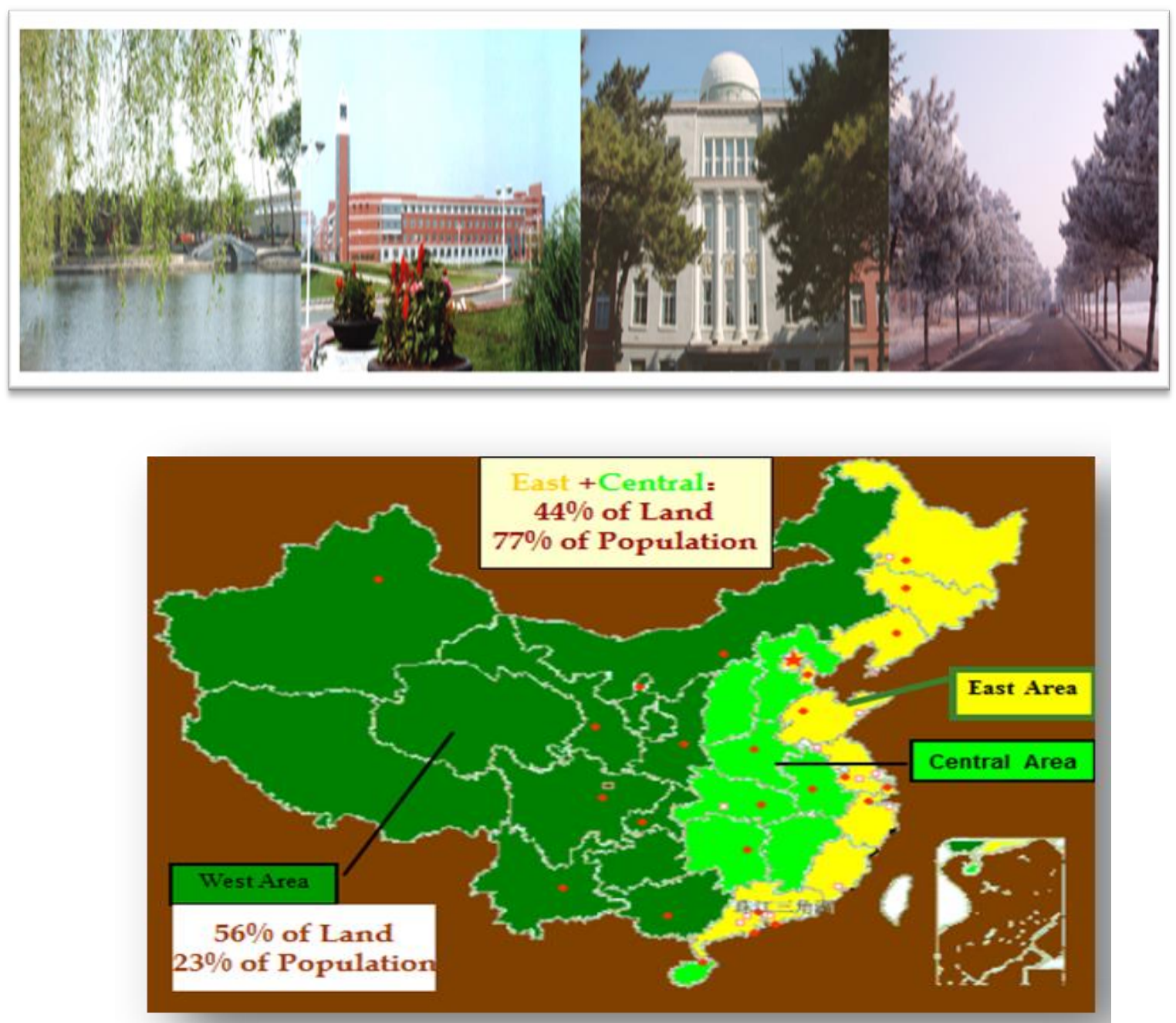

ALHAJI IN BEIJING
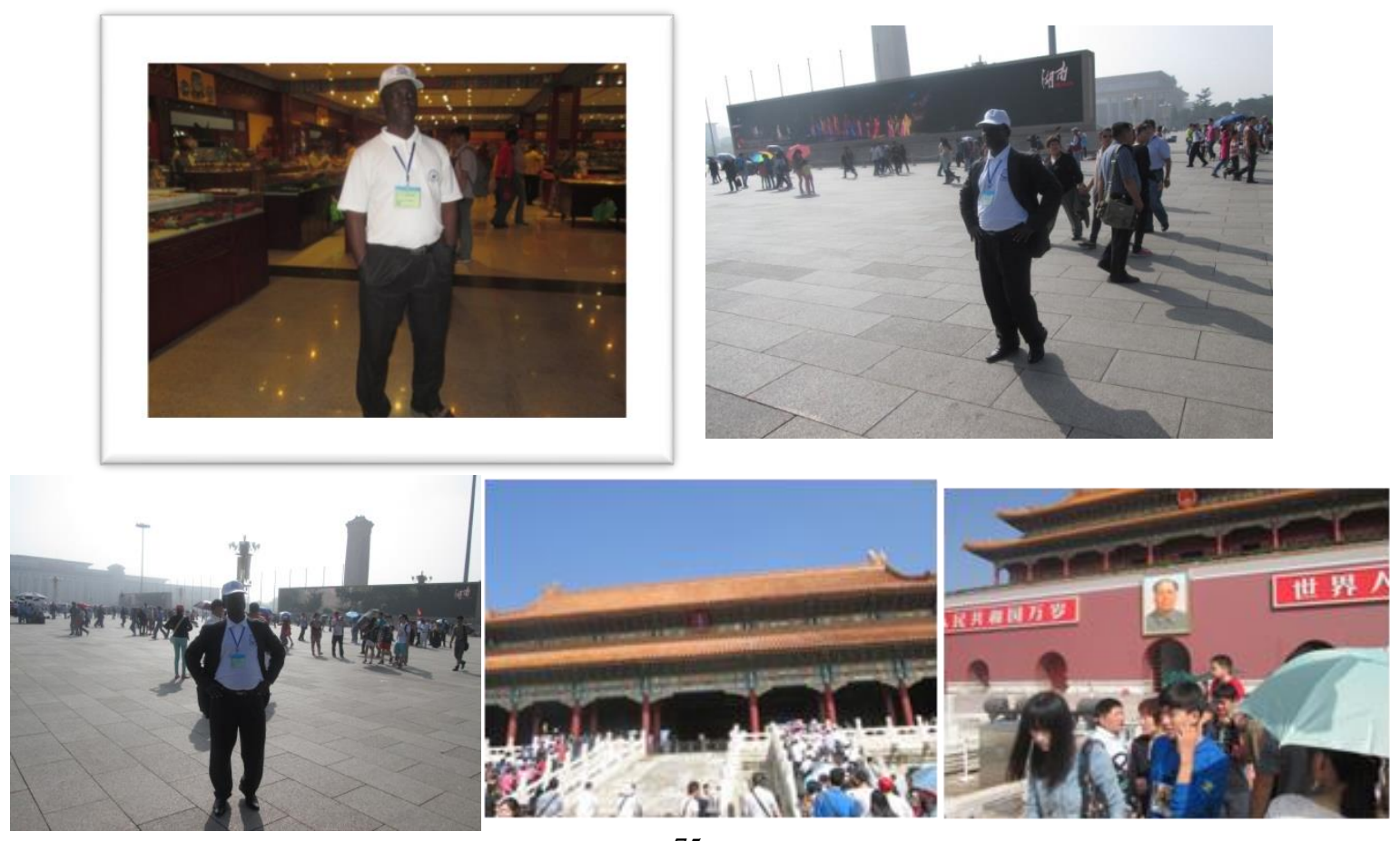


\section{Touring and Visitations around China}

After a comprehensive academic work for two weeks, participants were taken for touring to some important places in China as a field trip. Participants gained a lot of experiences in visiting cities like Beijing, Shanghai, Guangzhou, Hanghzou, Yiwu and many more.

\subsection{Beijing- The City of China}

Beijing, the capital of the People's Republic of China, is a world-famous historic city as well as a culturally famous city. Having a congregation of superb Chinese cultures and arts, and bearing the meaning of the rich culture of the Chinese nation, this millennium-old ancient city has abundant scenic spots, historical sites, and places of cultural interest, of every dynasty. The 5,000 years of the Chinese nation's civilization has stretched the height of perfection in this city, unfolding directly and brightly. It fully deserves to develop to the "cultural capital in the East" to attract world attention. Beijing bears multitudinous cultural residues that made it one of the cities that have most historical relics in the world. Amid them, the Forbidden City, the Great Wall, the Temple of Heaven, the Summer Palace, the Peking Man Site at Zhoukoudian, the Ming Tombs, the Tiananmen Square, the Beihai, the Yongle Bell, the Yunju Temple and many more. As a participant of the seminars, the author had a chance of visiting all those places with great admiration and experiences. In all these places the researcher visited, the ones that were admired most, were the Forbidden City and the Great Wall. As the researcher entered the compound of the Forbidden City, and climb the high attitude of the Great Wall, there was a feeling of admiration and respect for the clear manifestation of China long history of architectural talent. Really, Chinese still have strong preservation of those relics of the past, everything is well protected and properly conserved. (Zyppia, 2017)

\subsection{The Forbidden City}

The Forbidden City, also named as the Palace Museum, and GU GONG in Chinese, is located at the city center of Beijing, and formerly functioned as the majestic palace for 24 emperors during the Ming and Qing Dynasties (1368 1911). The Forbidden City was first constructed all through 14 years during the reign of Emperor Chengzu in the Ming Dynasty (1368-1644). Ancient Chinese Astronomers believed that the Purple Star (Polaris) was in the center of heaven and the Heavenly Emperor breathed in the Purple Palace. The Palace for the emperor on this world was so called the Purple City. It was forbidden to enter without distinguishing permission of the emperor. Henceforth, Its name: 'The Purple Forbidden City', normally 'The Forbidden City'. Present day known as the Palace Museum, it is to the north of Tiananmen Square. Rectangular in shape, it is the world's largest palace multifaceted and covers 74 hectares. Bounded by a 52 -meter-wide moat and a 10-meter-high wall with more than 8,700 rooms. The partition has an entrance on each side. The distance between the south Meridian Gate (Wumen) and the north Gate of Divine Prowess (Shenwumen) is 961 meters (1,051 yards), while the distance in the middle of the east and west gates is 753 meters ( 823 yards). There are unique and precisely structured towers on each of the four corners of the curtain wall. These give views over both the palace and the city outside. The Forbidden City is separated into two parts. The southern section or the Outer Court was where the emperor implemented his supreme power over the nation. The northern section or the Inner Court was where he stayed with his royal family.

The latter emperor of China was driven from the Inner Court in 1924, where fourteen emperors of the Ming dynasty and ten emperors of the Qing dynasty had reigned in it. It has been the imperial palace for some five centuries; Forbidden City houses many rare riches and curiosities. The UNESCO listed it as a World Cultural Heritage Site in 1987 (TravelchinaGuide, $21^{\text {st }}$ Anniversary). The author, as a student tourist, has visited this place starting 2013.

\subsection{The Great Wall}

The Great Wall of China is one of the greatest wonders of the world. It lies like a gargantuan dragon, it breezes up and down traversing the deserts, grasslands, mountains and plateaus, extending approximately 21,196 kilometers from east to west of China, with a justification of about 2,700 years. The Great Wall of China is an appealing attraction all around the world due to its architectural magnificence and historical importance. The Great Wall was constructed during the Ming Dynasty (1368 - 1644). It begins from Hushan in the east to Jiayuguan goes to the west crossing Liaoning, Hebei, Beijing, Tianjin, Shanxi, Inner Mongolia, Ningxia, Shaanxi, Gansu and Qinghai.

The Great Wall was initially constructed in the spring and autumn, and Combatant States Periods as a protective fortification by the three states: Yan, Zhao and Qin. It tunneled through continuous additions and repairs in later dynasties. Emperor Qin Shi Huang finally succeeded in his struggle to have the walls linked together to fend off the attacks from the Huns in the north. Since then, the Wall has aided as a monument of the Chinese nation all through history to date. 


\section{Traditional Festival List, Dates and Customs}

The observable scenery in China, and its people is a demonstration and manifestation of friendliness, love, harmony, oneness and co- existence. The contemplation of ghastly scenes renders a man to be callous to even a dreadful sight, but China is an exception, everything is under control morally. If only what was observed in China in terms of behavior and culture, is a prevailing cultural environments of so many countries world -wide, Mankind generally stand a chance to enjoy the reality of humanity in terms of dignity, respect, peacefulness, humility, independency, hardworking, dedication, endurance and self-reliance. In reality, the traditions of Chinese ethical behavior is centrally concerned with the question about the way to live: what energies into meaningful life, how steadiness in duties towards family versus duties towards strangers, whether human nature is likely to be morally good or bad, how one performed to be in the non-human world, the level to which one should develop involve in restructuring the greater social and political buildings of one's society, and how one must conduct oneself when in a situation of influence or power (Kamara Alhajie Bakar, 2018).

From the lectures of the seminars, a knowledge of traditional Festivals in China categorized by varied styles and themes, traditional Chinese festivals are an important part of the country's history and culture, both ancient and modern. Many of the customs are associated with the traditional festivals have relations with religious devotions, irrational belief and myths. The system which most of the festivals proceeds nowadays was traditional around the period of the Han Dynasty (206BC - 220) and for several years, numerous eminent composers have inscribed uncountable masterworks describing the festivals and are still narrated frequently in the present day.

Virtually every festival has its own exceptional roots and customs which replicate the traditional practices and morality of the whole Chinese nation and its people. The unresolved and most predominant festivals are the Chinese New Year (Spring Festival), the Lantern Festival, the Qingming Festival, the Dragon Boat Festival, the Mid-autumn Festival, etc. Traditional festival was also shared. Here are the list of traditional festival, their dates and customs:

- Chinese New Year - 1st - 15th of the first lunar month- pasting scrolls, the character 'Fu', and paper-cuts pictures, setting-off firecrackers and fireworks, paying New Year visits, and eating jiaozi.

- Lantern Festival- 15th day of the first lunar month- watching lanterns and fireworks, guessing lantern riddles, performing folk dances, and eating yuanxiao.

- Qingming Festival -April 4th or 5th of the solar calendar-tomb sweeping, spring outings, and flying kites.

- Dragon Boat Festival - 5th day of the 5th lunar month - dragon boat racing, eating zongzi, wearing a perfume pouch and tying five-colour silk thread, and hanging mugwort leaves and calamus.

- Double Seventh Festival- 7th day of seventh lunar month- praying for skillful hands, appreciating the stars, and eating noodles, jiaozi, and wontons.

- Mid-autumn Festival- 15th day of the 8th lunar month-appreciating and offering sacrifice to the moonlight and eating moon cakes.

- Double Ninth Festival-9th day of the 9th lunar month-eating Chongyang cake, drinking chrysanthemum wine, climbing mountains and appreciating beautiful chrysanthemums.

- Winter Solstice- Dec. 21st, 22nd or 23rd in solar calendar- having dumplings in northern areas and having sticky puddings in southern areas

- Laba Festival - 8th day of the 12th lunar month- eating laba rice porridge.

Chinese architecture has certain distinct structures. They are as follows:

- Chinese architecture has always been in harmony with nature. Chinese architecture de-emphasizes vertical walls.

- The country's architecture is highly symmetrical, which theoretically supports the proper order of things and signifies a sense of stately greatness.

- Chinese architecture has reserved certain designs for people of different status. Aspects of the building such as height, color, material, and size of the house were all regulated by law according to rank of the family living there.

(https://www.trippest.com/chinese-culture-guide/traditional-chinese-festivals-2019/) 
Alhaji in Tiananmen Square and Forbidden City
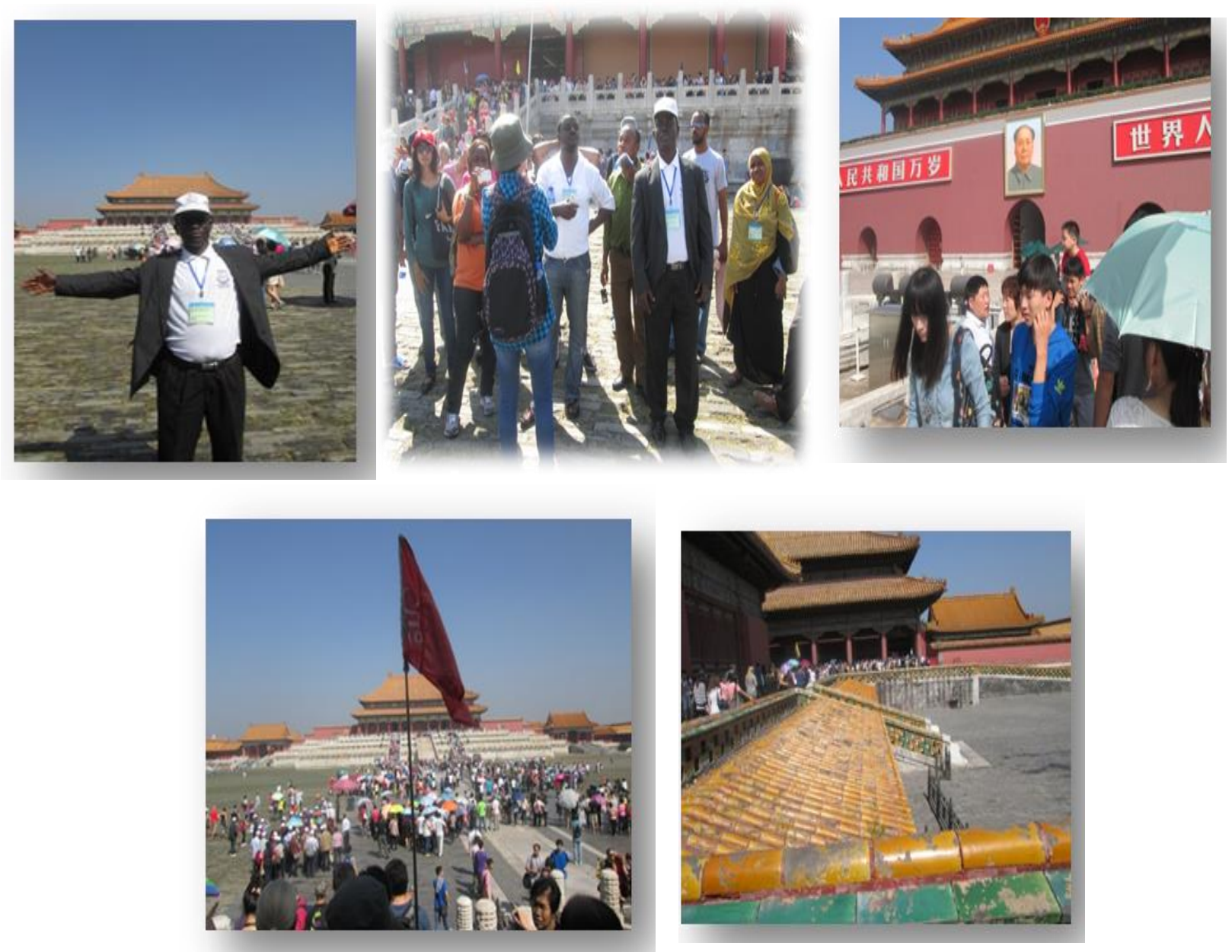

\subsection{Shanghai Oriental Pearl Radio \&TV Tower}

Shanghai is the most beautiful city the researcher have ever seen in China. The Oriental Pearl Radio \& TV Tower is very attractive both outside and inside. The tower bears a lot of other facilities such as : Space capsule Sightseeing Floor, Transparent observatory, Game City, City Gallery, Shanghai History Museum, No 8 old Shanghai Restaurant, Old Shanghai -style street, OPG Souvenir, the Shanghai show, Chocoholic shop, Coke-Cola Bar, Flower Bar, Wedding and Book store. The 270 degree Circular windows present Breathtaking Signs of the Huangpu River. Facts about this Radio\& TV Tower:

Established since: 1991

Completed in: 1995

Overall Height: 468 meters (1,536 feet)

Height of Observation Decks:

$351 \mathrm{~m}$ (1,152ft): Space Capsule Sightseeing Floor

267m (876ft): Revolving Restaurant

263m (863ft): Main Sightseeing Floor

259m (850ft): Glass Floor

90m \& 98m (295ft \& 322ft): Game City including an indoor roller coaster

$78 \mathrm{~m} \quad$ (256ft): Dynamic Ring $\quad$ Multimedia

(https://www.travelchinaguide.com/attraction/shanghai/oriental_pearl.htm) 

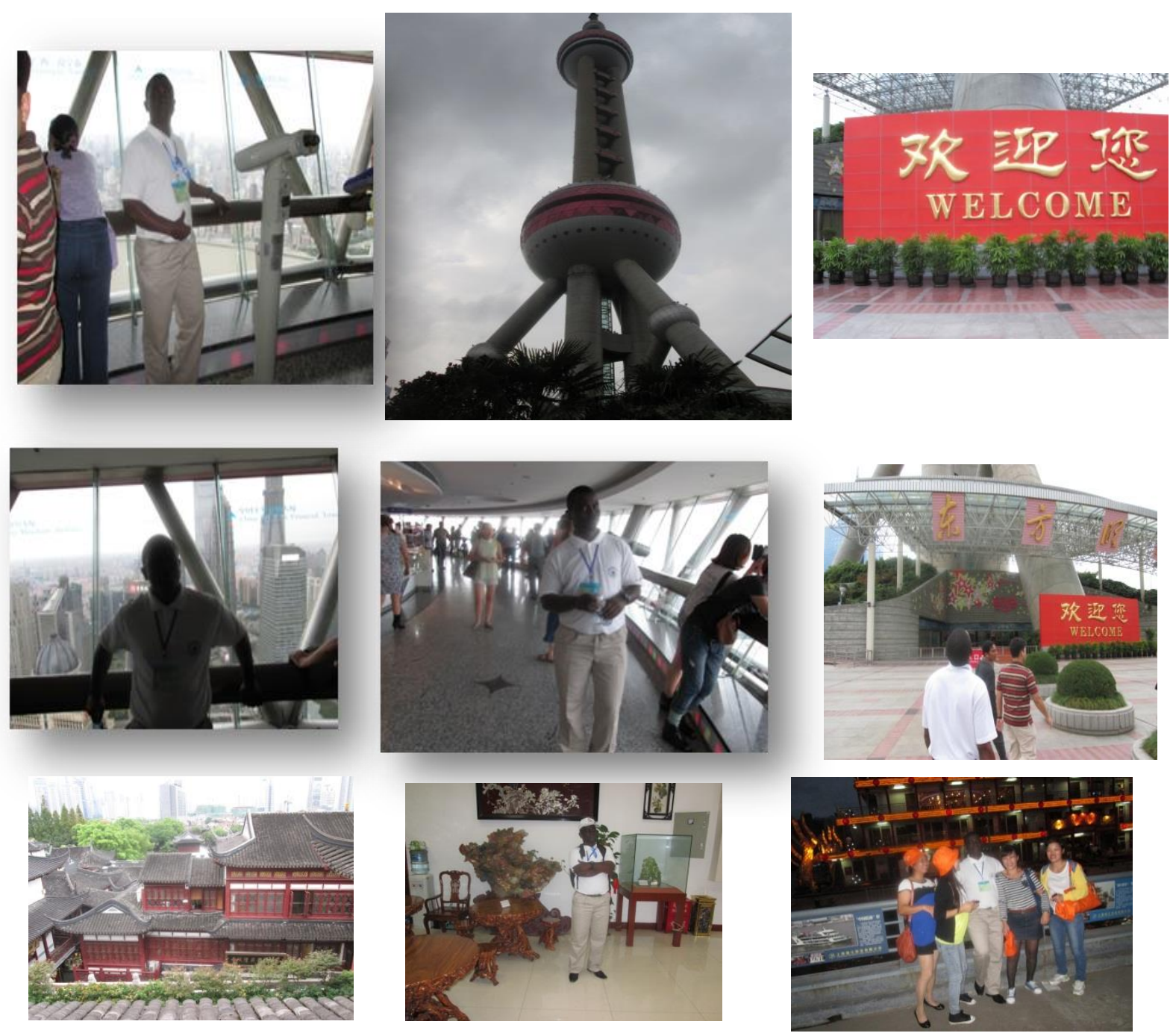

\subsection{Forms of Transportation in China}

In the travel experiences, the organizers exposed participants to all forms of transportation in China. In the daily tour within the cities, participants were made to taste the frequent use of Government buses. They used Air planes and High speed train to travel from one city to another. It was a wonderful experience. In addition, they were also taken to rural areas that used boats as form of transportation from one area to another. As a participant, the researcher also traveled from one location to another with boats as a means of transportation. There was a really good experience of rural life in China's rural settings. The researcher and some participants were fortunate to see the old bus transportation in Beijing. The transportation facilities in China is well coordinated and planned. It has separate entity of administration. Public buses, taxies, bicycles are the most common vehicles for someone to take. In some new and developed Chinese cities, subway, light rail and even Maglev trains can all be measured as good means for someone to get around the city. In China, almost all major cities are equipped with a developed bus transport system

According to the lectures in the seminars, the transportation system in China has developed dramatically since 1949. These days, China has a wide-ranging transportation system of airports, trains, highways, subways, ports, and waterways. Amid these, high-speed rail lines, highways, and numerous new subways, have perhaps upgraded the daily lives of indigenous people most radically.

Airlines in China provide safe and comfortable service for travelers. Most airlines and airports provide world-class services and facilities. They are all controlled by the General Administration of Civil Aviation of China (CAAC). The following are the key dependable airlines in China: Air China Limited, Eastern Airlines, Southern Airlines, Hainan Airlines, Shenzhen Airlines, Shandong Airlines, Shanghai Airlines, Sichuan Airlines, and Xiamen Airlines. 

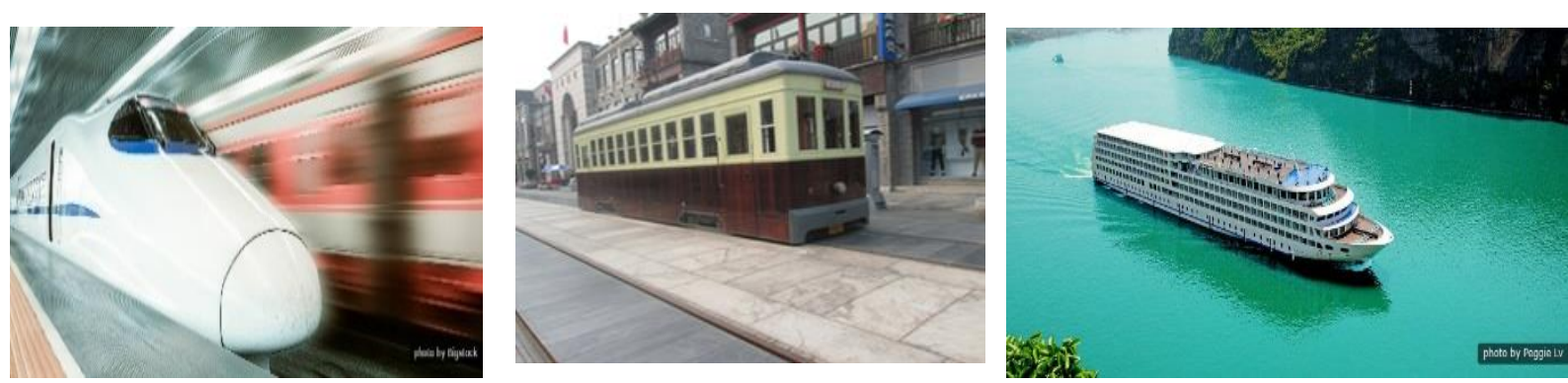

RAIL-The train is one of the key way of transportation in China and the national rail network is one of the biggest of the world. The whole mileage of railways open to traffic in China sums to 124 thousand kilometers. The number of passengers conveyed by train has stretched 2.5 billion. Chinese railway service boasts internal and international operations. The Chinese railway system is 124,000 kilometers long in aggregate, of which 22,000 km belong to high speed railways. These railways cover almost every place in China, even isolated mountainous areas, plateaus, and the seaside. High-speed rail (HSR) in China is the country's network of passengers- devoted railways designed for speeds of 250-350 Kilometers per hour $(\mathrm{km} / \mathrm{h})$. By the conclusion of 2018, China's HSR stretched to 29 of the mainland's 31 provinces, autonomous regions and municipality, and the railways extended a combined 29,000 kilometers in length, which account for about two-thirds of the world's high-speed rail pathways in commercial service. Facilities on these trains are comparable to those on an airplane. The seats can always pleasantly adjust to the moving path; the seatback can be adjusted to the anticipated angle; a foldable small table is accessible for each seat; and electrical sockets are available in respective row or compartment. Besides, meals and snacks are delivered at a reasonable price (https://www.travelchinaguide.com/cityguides/beijing/forbidden.htm).

\subsection{Transportation in Waters}

China has 110,000 kilometers of seaworthy rivers, streams, lakes, and canals, the longest than any country in the world. The Heilong Jiang; Yangtze River; Xiang River, a short branch of the Yangtze; Pearl River; Huangpu River; Lijiang River; and Xi Jiang are the main ones. The Grand Canal is the world's longest canal at 1,794 km and functions for 17 cities between Beijing and Hangzhou. It links five major rivers: the Haihe, Huaihe, Huanghe, Qiantang, and Yangtze. Creation of new railways and highways has reduced the use of China's rivers for passenger transport.

However, passenger boats are still common in some mountainous regions, such as Western Hubei and Chongqing (the Three Gorges area), where railways are few and road entries leading to many towns is problematic. In big cities, buses are many and the scheme works rather well. Even if you are not a native speaker of Chinese, you can cope, on situation of taking a map with the names of the streets in native Chinese. There should be no hesitation to authenticate the journey's end with a Chinese traveler.
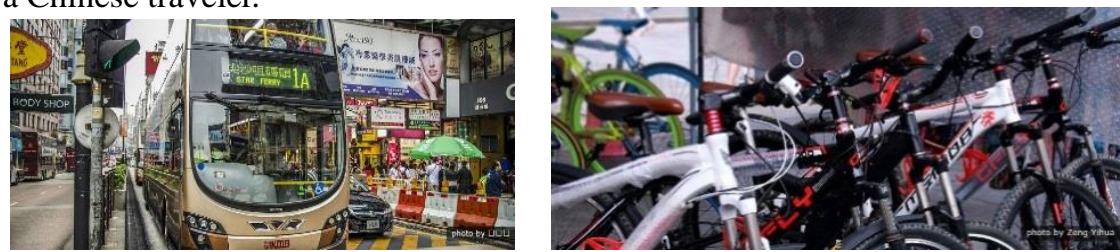

There had been a system of renting Bicycles from particular agencies. Today, the Government has improved that burden from citizens by providing public bicycle services in many cities to inspire low-carbon traveling. Public bikes can be seen on definite places of streets so that it is very convenient for people to acquire one. In as much as your cell phone has the function of Alipay or WeChat Payment, you can simply rent a public bicycle minus applying for a permanent card for renting (https://www.chinatravel.com/facts/china-transport.htm).

\subsection{Communication}

As learnt and experienced in China during the seminars, WECHAT and ALIPAY are the prominent channel of communication and transaction in China. The services of these two applications provide a wider range of human satisfaction and are very effective. In fact, WeChat and Alipay services are almost kicking away and bidding farewell to cellphones. In China, mobile payment has brought numerous changes to everyday activities of people. These applications- WeChat and Alipay- are already creating a new thing, which can permit people to pay without your phone.

These two applications have transformed a lot of people's lives, because people do not have to carry money in cash that may be exposed to thieves and criminals. People only need to use their phones, scan the QR Code, and input their passwords. Presently, there is an ongoing process that uses "facial recognition" for future transaction. Besides, IPhone X and many others are presently using this function in more and more areas as follows: 


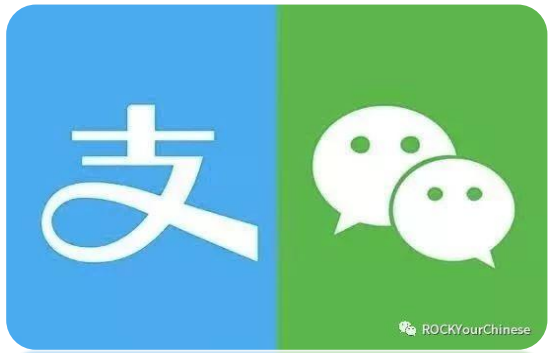

\subsubsection{Restaurant}

Many restaurants have started using Alipay's "facial recognition". People do not need to their phones and passwords any more. Their unique faces are the new QR Code. But truly it exposes a problem to identical twins, the author observed.
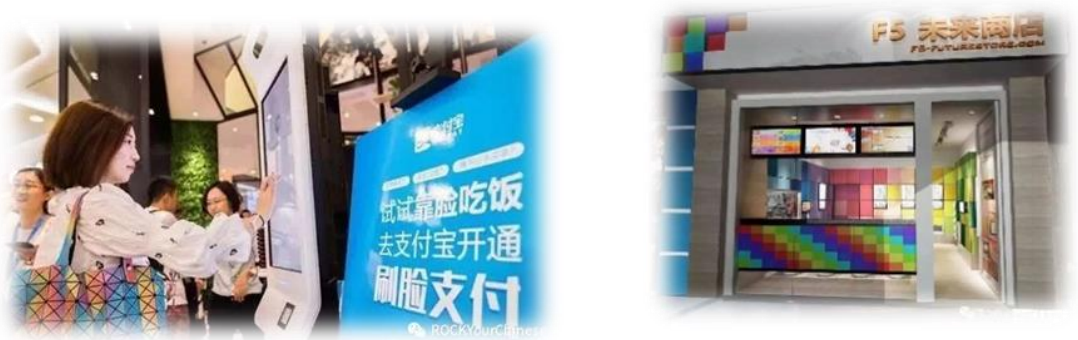

\subsubsection{Supermarkets}

The researcher also learnt that, Ma Yun, the richest Chinese guy, invested in a new supermarket, and that supermarket do not have shop assistants. People only show their faces in a particular screen in the shop when they want to buy goods from that shop. That system is now in operation in Beijing - check in kinda supermarket, it is very popular for this.

\subsubsection{Bank}

There is also a proposal to implement the use of "facial recognition" in certain Banks in all cities in China. This system is thought fit for college students because there are at times when students do lose their college cards or Bank card. With such problems, those students' faces can easily be identified by the system .So preferably, ABC Bank can be used.
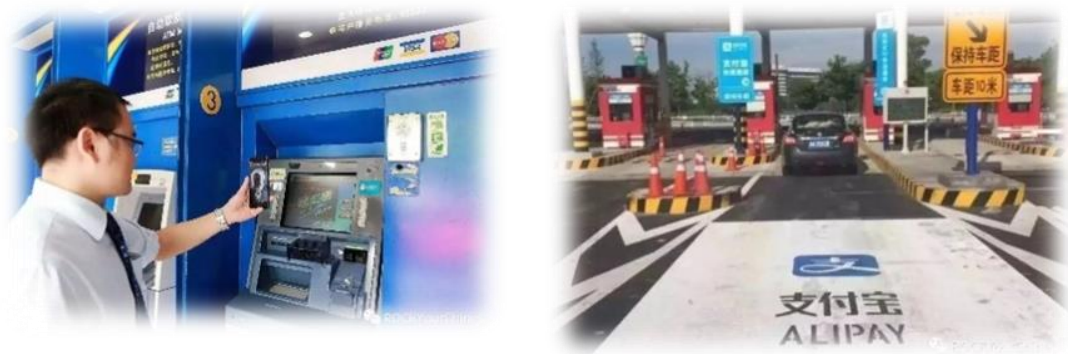

Besides, the system can also be used to easily pay for passes through highways, as there is always a need to pay money by cash. But now, even those expressways don't need to use cash.

This can be done by just binding the information with the car's plate number. So at any time that person is free to pass without having to stop and wait for the long line. The system charges the money from that person's Alipay automatically. This system save people's time a lot.
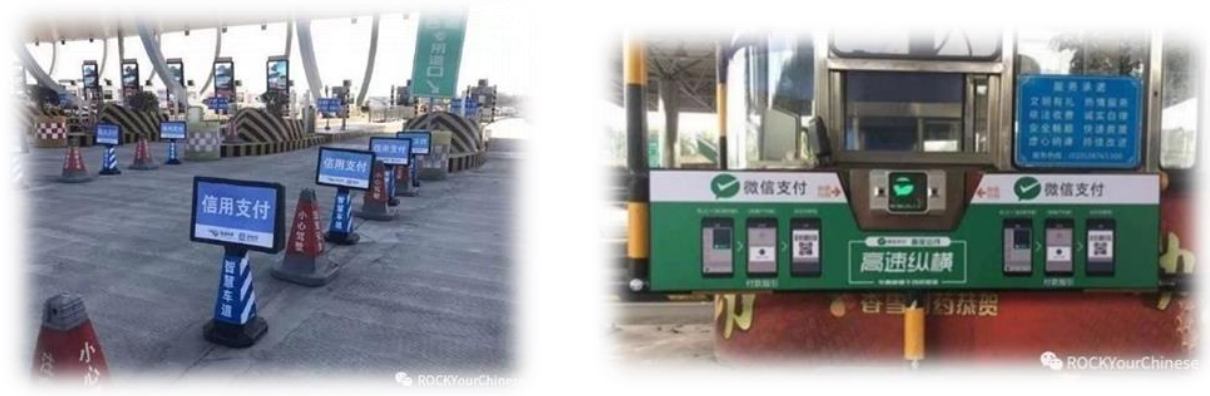
(But really, this system is not $100 \%$ safe to let some people or some machines collect people's money without password). Therefore, WeChat today has introduced a new feature that allows people to have a new account to pre-save some money in it, and will collect money from this account after the driver used freeway, and the company will send the driver a text (Sabrina ROCKYourChinese, 2018).

In admiration, the author anticipated to have such opportunities in all developing countries. If not, it is necessary for any country without these facilities to seek the operation of WeChat and Alipay in their countries through association and friendly co-operation with China. These apps are operational in almost all part in the world through the availability of internet. As a student, the author has used it in Sierra Leone in checking for information from the University during the research holiday. A friend of the author had proved using it in Ghana- in fact the wife of that friend is communicating to that friend every day through WeChat. Ember Swift - a Canadian writer and an International touring musician- also indicated some benefit of WeChat in the article, “Chinese Apps I Love: How Will I Live Without Them?"(WOMEN OF CHINA, Breaking Barriers, September, 2017).

\subsubsection{Acrobatic Performance}

Participants were also taken to the acrobatic life performance. Unfortunately, they were restricted from taking a snap shot or video during the performances; so there was no record of those performances. The performances were very amazing and interesting. The researcher personally used to watch Chinese films thinking it was just a computer work, but the life views of those performances really instill more credit to the Chinese people for their gifts and talents.

\subsection{Graduation Ceremony for Participants}

Before the end of any seminar, a grand graduation ceremony was observed as a farewell party for the participants. To climax the ceremony all participants are given option to choose the type, color and style they would like to wear for the ceremony. The dress is very unique, neat and respectable to wear as an intellectual. The dress also adds credit to the participants when they return to their home countries.
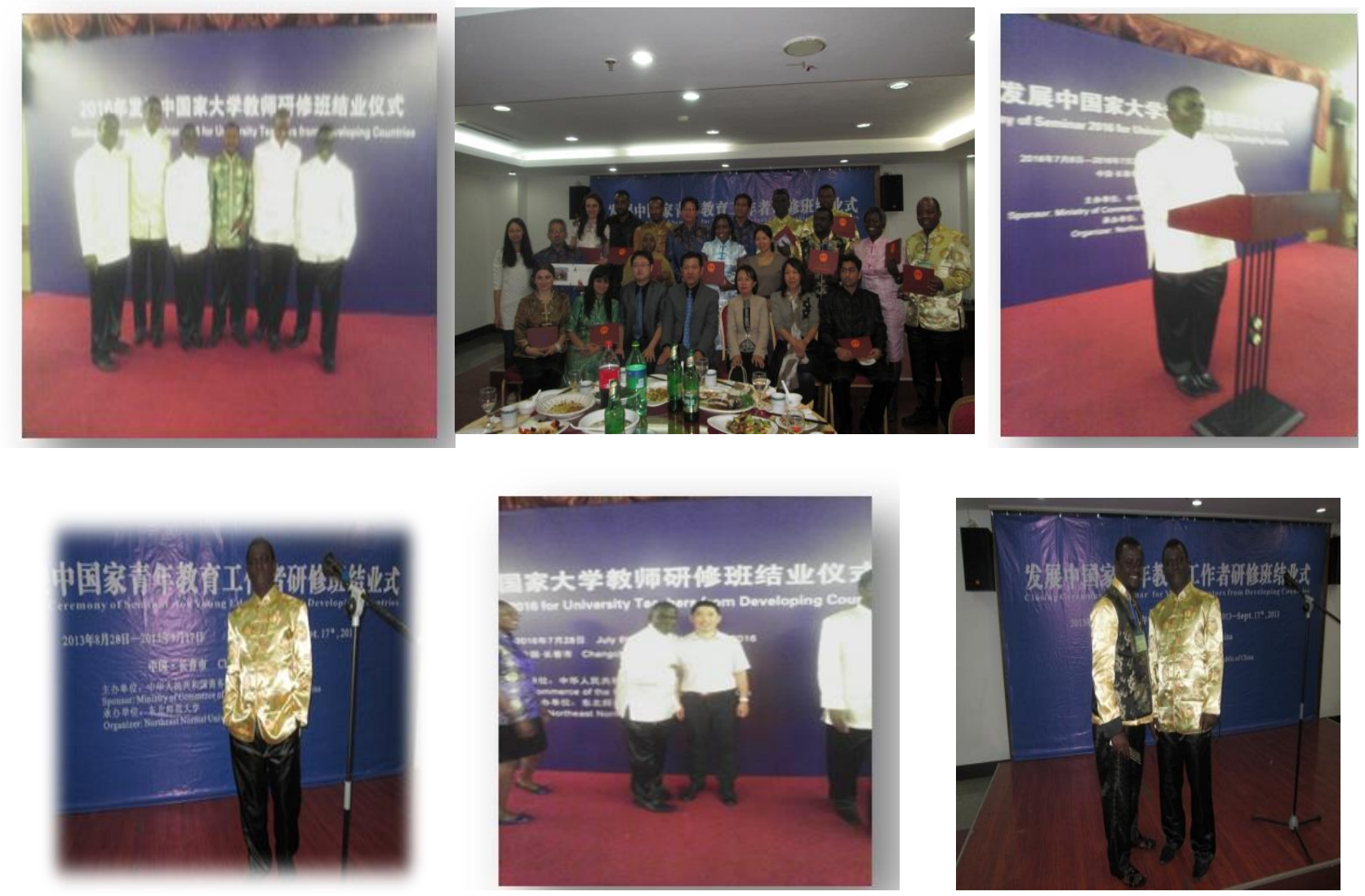

The researcher and other participants also visited many places in Beijing, Shanghai, Changchun Cities, and Universities like Zhejiang Normal University in Jinhou, Quzhou University in Zhejiang province, and South China Normal University in Guangzhou and Army academy in Guangzhou. 

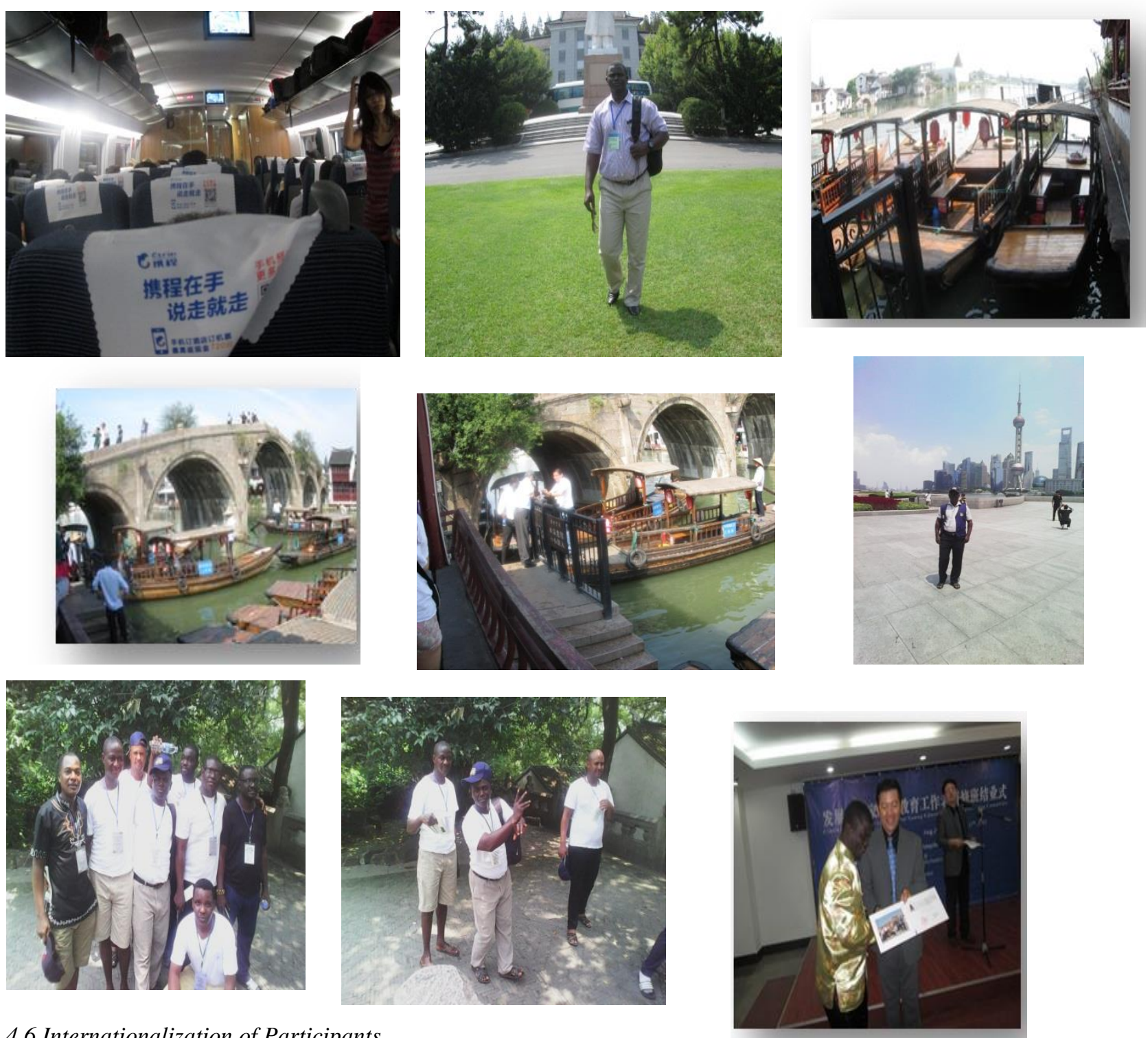

\subsection{Internationalization of Participants}

The seminars also promote global integration. Participants from different countries meet with different personalities that interact together to build a strong relationship of co-operation and bilateral internship that help to develop their countries. People become everlasting friends that help each other with more opportunities in education, co-operation, and many more. Each country has the opportunity of making a presentation of its own country, whereby other participants understand the educational systems of other countries. Participants benefit a lot in comparing and contrasting their own countries with others. Participants also do some shopping of various goods during seminars in China. This helps them to take along valuable items and goods to their countries in advertising and promoting China. The seminars are also another method of internationalization and globalization. It nurtures global markets and competition between organizations or nations with China. It is a means of transporting the monitoring frameworks of educational structures with the philosophies of exporting and importing nations closer together. It also accelerated the global transmission of innovative public management replicas and educational Chinese characteristics. Mainly in the method of on-shore education in the exporting nation like China, it also has transformative consequences for the participants undergoing these training in China. Participants absorb into their identities the multicultural experience and the norms of mobility and some remain globally mobile later in their careers. Seminar in China are providing places to foreign students to have the tendency and potentiality of diversification in different curricula and pedagogy. China has developed a closer familiarity with seminars in importing nations in order to facilitate recruitment and to align programs and recognition arrangements. International education generates organizational circumstances supporting other forms of alliance in research collaboration, student and faculty exchange, quality assurance and benchmarking. 

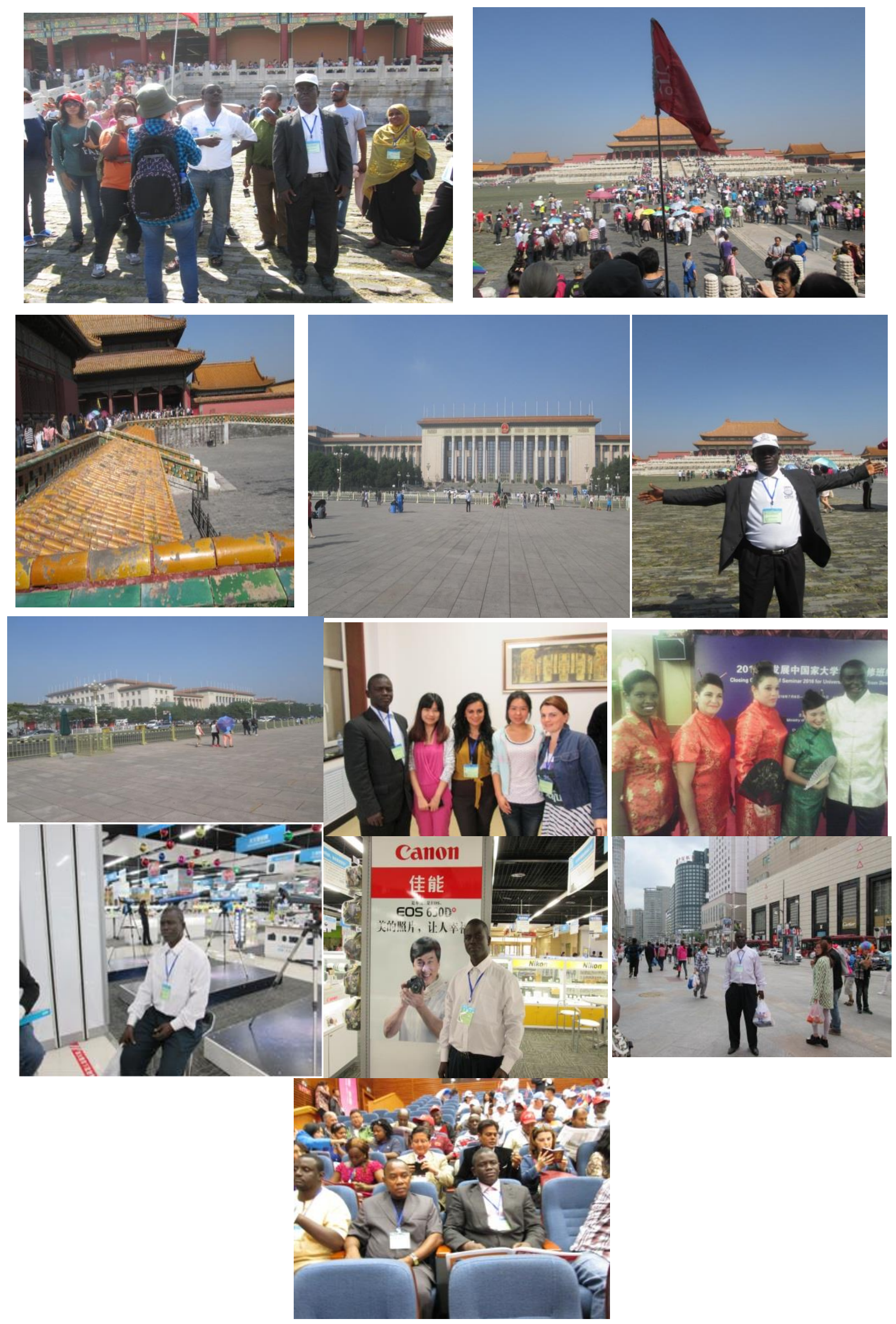


\section{Relevance and Significance of the Seminar in China}

In today's globalized world, and in a knowledge-based economy, we have seen the emergence of knowledge as a major driver of growth in the context of the global economy, the information and communication revolution, the emergence of a worldwide labor market, and global social-political transformations. A tertiary education plays a key role in acquiring and building this knowledge. But the poor / developing nations have been lagging behind when it comes to tertiary education, and a key concern is whether these countries will be able to adapt and shape their tertiary educational systems to confront the challenges of keeping up with today's' knowledge-based globalized world.

Advantages among nations come less and less from abundant natural resources or cheap labor and increasingly from technical innovations and/or the competitive use of knowledge - an example of this is the success story of the People's Republic of China and its open-up policy. But the developing nations are ignoring their educational seminars/trainings in terms of investment. One of the main reasons for the gap in agricultural productivity between industrial and developing countries is that advanced economies spend up to five times more on agriculture related to their counterparts in developing countries. Also, educational seminars/ trainings are some of the most influential of the set of complex factors that determine the productivity and growth for a given economy. But it is important to note that the developed nations possess the critical combination of infrastructure, expertise, and the organizational and incentive structures in place, that allows these investments to be productive visa vie Foreign Direct Investment (FDI) (Congman Rao, 2013).

Seminars/Trainings in China help to alleviate poverty and also helps support basic educational system of other developing countries. Seminars/Trainings in China help the building of a democratic, knowledge-driven societies that include: Supporting innovation by generating new knowledge, accessing global stores of knowledge and putting it to local use. It also Contribute to human capital development by training a qualified and adaptable labor force, including high-level scientists, professionals, technicians, basic and professional administrative teachers, and future governments, civil service, and business leaders. Moreover, seminars provide the foundation for democracy, nation building, and social cohesion.
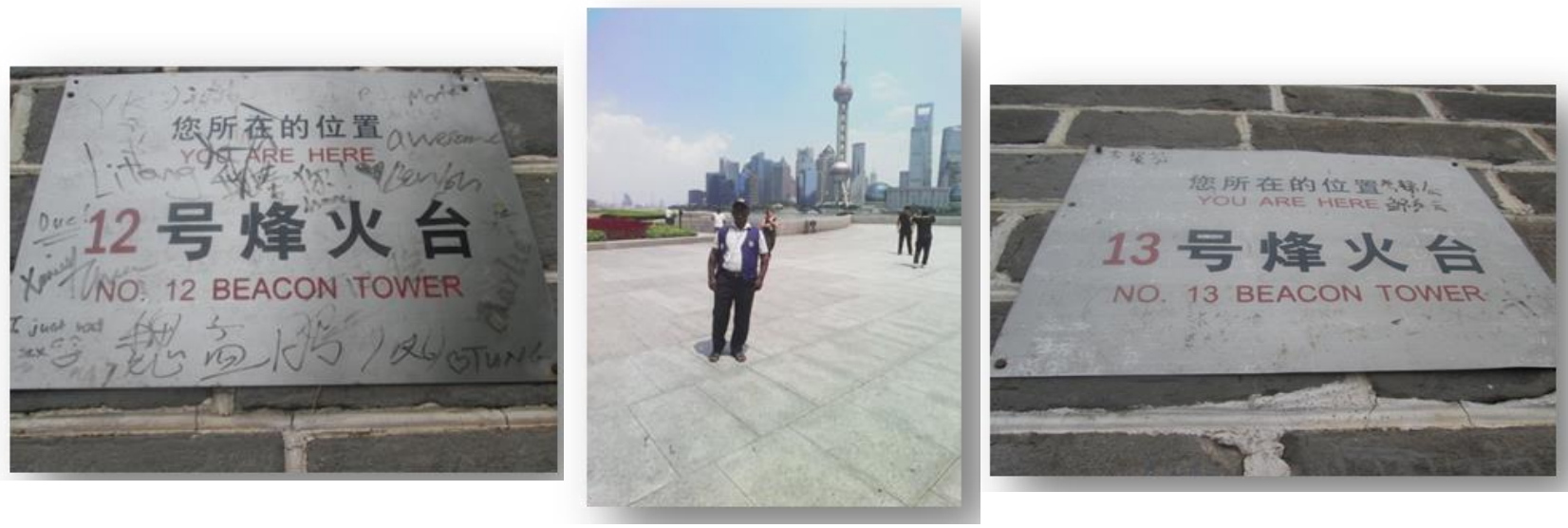

Alhaji in Various Places in Beijing and Shanghai-The Great Wall
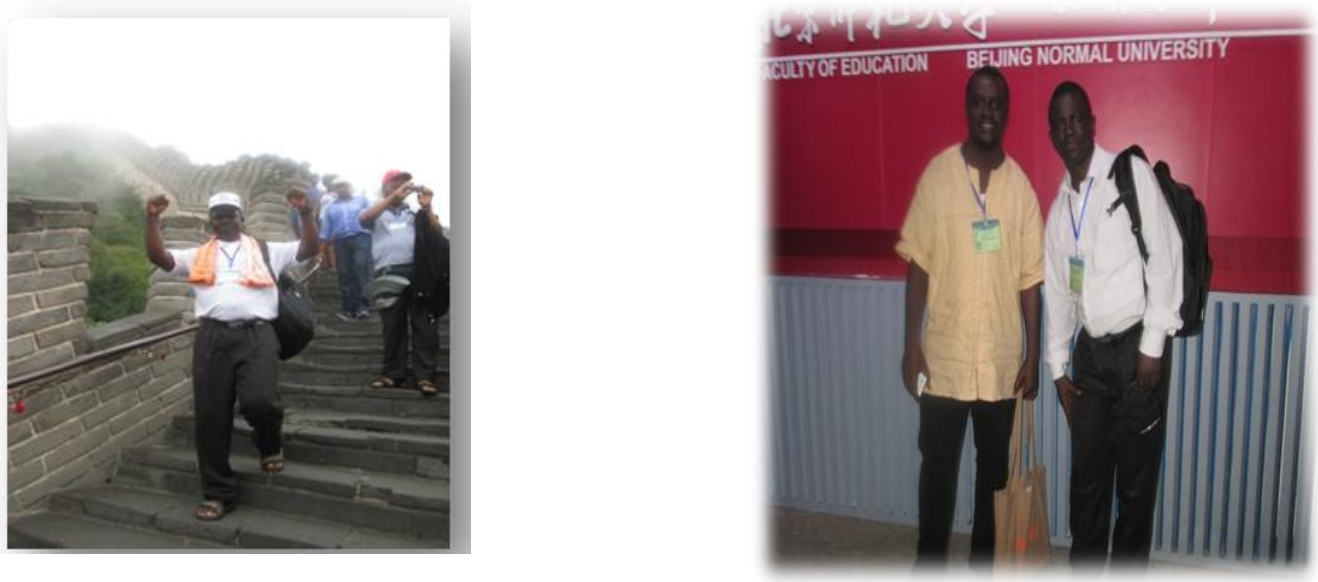


\section{Summary}

Seminars in China build a strong platform in Developing Countries through which Social and economic progress is achieved principally through the advancement and application of knowledge.

$>$ Seminar/ Training is necessary for the creation, diffusion and application of knowledge, and for building of technical and professional capacity of the manpower labor of Developing Countries.

$>$ Seminars/Training empower Developing countries to withstand the risk of being further marginalized in a highly competitive world economy because of the poor quality of their tertiary education systems.

$>$ Seminars/Trainings provide educational, social and philosophical knowledge to Developing Countries to realize their responsibilities and challenges. This will lead them to put in place a framework for the educational institutions to be more innovative and responsive to the needs of a globally competitive knowledge economy, and the changing labor market necessities for progressive human capital.

$>$ Seminars/Training in China is an act of attraction to foreign countries to feel the true culture and tradition of Chinese people. It gives the golden opportunity to foreign national to visit various places in China that will give an insight of admiration to the heritage and transformation of China.

$>$ China also act as a base for the unification of humanity to share common characteristics by making it possible for people to be friends all over the world through internationalization. Different people from different backgrounds meet in one seminar to share common values, cultures, traditions and aspirations. Being together foster friendship and brotherhood that give birth to international co-operation.

\subsection{Recommendations}

1. The content of these seminars could be developed as modules for a post graduate diploma in Education program covering a period of one year. The content of the seminars is reach in knowledge, so it needs an extension of more time than a month for proper evaluation of the participants

2. The organizers must always prepare a booklet of all the lectures for the seminar, and each participant should have one copy before the beginning of the seminar. This is to give chance to participants to read ahead before any lecture (this is very common for seminars held in Changchun, North-East Normal University- usually, participants are provided with reading material).

3. Besides, organizers should be trained for the job of coordinating and administering higher personalities from developing countries, the code of dress and manners of approach, time management and gender are very important.

4. All notes presented should be in English for participants to understand (for Anglophone countries).

5. Extra curricula activities to be included in the program for participants to exercise everyday their bodies in order the kick away tiredness when there are no classes.

6. It is advisable that the government empowers participants in projects to promote the activities of China-Sierra Leone co-operation and exchange programs in their home countries.

7. It is also recommended that China to extends or strengthens educational base-activities in the rural environs of Sierra Leone by establishing educational institutions that will ferment the cooperation between China and Sierra Leone.

8. It is finally recommended that Chinese government promotes a joint research projects between Sierra Leonechina, and continue the exchange programs to ensure the sponsorship of research to Sierra Leone is sustainable 

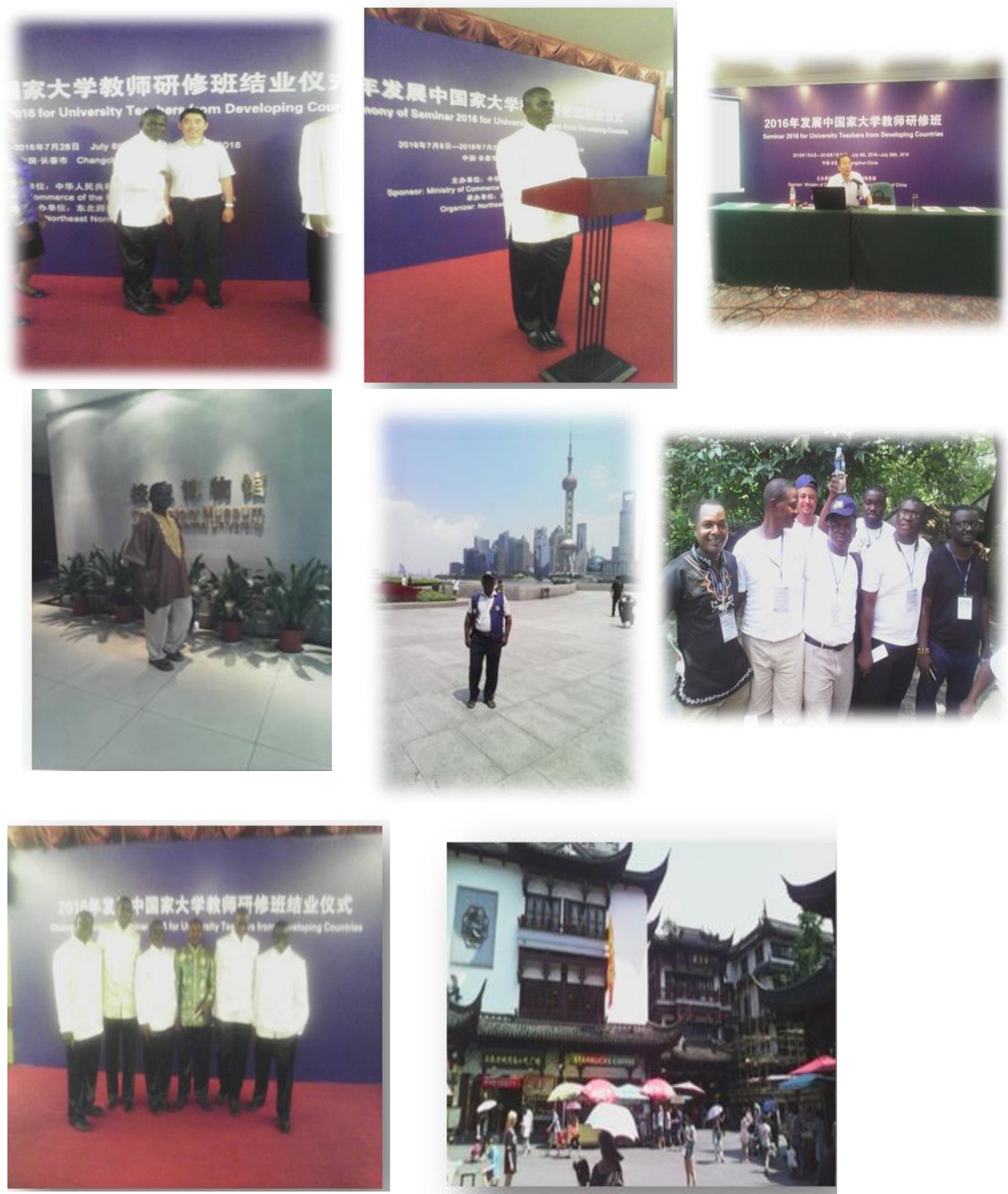

\subsection{Conclusion}

Seminars and Trainings in China is a tradition in augmenting the knowledge of people within a very short time. All sectors of development uses it as weapon to speedily recruit the labor force within any locality in the municipality. In businesses, Education, Agriculture, commerce, medicine, military, foreign affairs, marine, communication and many more, seminars and training bring about changes of improvement for better outcome. The seminars attended in China were very reach in knowledge for the administration of Higher Educational Institutions. All lectures were very relevant to all participants who came from different Higher Institutions in different countries in Africa. The facilitators (lecturers) were all professional from Universities and ex-professors now working for the Government.

The seminars also paved way for participants to learn from each other since all participants made presentations of their 
Higher Educational stands in their countries. The touring and visitations widen the scope of the participants to know and learn the infrastructural, cultural and technological development of China and Chinese people. The seminars are climax with grand graduation.

The touring also gave a practical experience to the participants based on the lessons learnt from the seminar.

The participants were very much appreciative of the experience and exposure gained from China Seminars. Many are determined to make a change in their individual counties by implementing what they learnt from the seminars. It is believed that, changes in people's thoughts, behaviors, cultures, policies and laws will lead to sustainable growth and development in developing countries.

\section{References}

Bah, M. C. (2019). The Growing influence of China in Sierra Leone. News Paper, Sierra Leone press. Standard Times Press, Newspaper. http://standardtimespress.org/?m=201903

CEBEX and IAseminar, (2012). "CEBEX Group and IASeminars offer IFRS and US GAAP training in China". www.cebexgroup.com /www.ce180.com or www.iaseminars.com

China Transportation, (2019). Transport System in China. Retrieved from https://www.chinatravel.com/facts/china-transport.htm

Congman, R. (2013). 'The Reform and Development of Teacher Education in China and Japan in an Era of Social,' in Eija Kimonen \& Raimo Kimonen (Eds.). Transforming Teachers' Work Globally: In Search of a Better Way for Schools and Their Communities. Rotterdam: Sense Publisher.

Ember, S. (2017). Chinese Apps I Love: How Will I Live Without Them?” Breaking Barriers, WOMEN OF CHINA Magazine, September, 2017.

Kamara, A. B. (2018). Chinese Films, Traditions and Cultural Heritage: An impact in Sierra Leone. https://oapub.org/soc/index.php/Ejsss/article/view/488/1069. Retrieved APRIL. 2019

Mauricia, J. (2013). Freetown Bond: a life under two flags, African Identities, 11:4, 407-408, https://doi.org/10.1080/14725843.2014.885780

Sabrina ROCKYourChinese, (2018). WeChat Latest Version: The Significant Changes-Instagram 2.0? Central China Normal University, International Exchange Department. Office 206 WeChat notices 2018-04-02 (unpublished)

Travelchina Guide (21st Anniversary), $\quad$ (2019). Oriental Pearl https://www.travelchinaguide.com/attraction/shanghai/oriental_pearl.htm)

TravelchinaGuide (21 ${ }^{\text {st }}$ Anniversary), (2019). https://www.travelchinaguide.com/

TravelchinaGuide (21st Anniversary), (2019). Traditional Chinese Festivals 2019: List, Dates, and Customs. (https://www.trippest.com/chinese-culture-guide/traditional-chinese-festivals-2019/)

Xinhua Daily Telegraph, (2013). Xinhua Daily Telegraph Special Issue. Xinhua News Agency Press. http://www.chinadaily.com.cn/rss/cndy_rss.xml

Yang, H. (2013). Important of Chinese language to promote Tourism in Nepal, EMBASSY OF THE PEOPLE'S REPUBLIC OF CHINA IN THE FEDERAL DEMOCRATIC REPUBLIC OF NEPAL ALL RIGHTS RESERVED http://np.chinesembassy.org. Seminar on January 25, 2013.

Zyppia, (2017). Beijing: The Capital City Of China. National Pedia (https://www.nationalpedia.com/beijing-the-capital-city-of-china/) March 19, 2017

\section{Copyrights}

Copyright for this article is retained by the author(s), with first publication rights granted to the journal.

This is an open-access article distributed under the terms and conditions of the Creative Commons Attribution license which permits unrestricted use, distribution, and reproduction in any medium, provided the original work is properly cited. 